\title{
Train Noise - Comparison of Prediction Methods
}

\author{
M. NĚMeC ${ }^{a, *}$, A. Danihelová ${ }^{b}$, M. Gejdoš ${ }^{c}$, T. Gergel ${ }^{a}$, Z. Danihelová ${ }^{d}$, J. Suchomel $^{c}$ \\ AND M. ČULÍK ${ }^{e}$ \\ ${ }^{a}$ Department of Physics, Electrical Engineering and Applied Mechanics, Technical University in Zvolen, Slovakia \\ ${ }^{b}$ Department of Fire Protection, Technical University in Zvolen, Slovakia \\ ${ }^{c}$ Department of Forest Harvesting, Logistics and Ameliorations, Technical University in Zvolen, \\ Faculty of Forestry, Slovakia \\ ${ }^{d}$ The Institute of Foreign Languages, Technical University in Zvolen, Slovakia \\ ${ }^{e}$ Technical University in Zvolen, Slovakia
}

\begin{abstract}
Railway noise in towns and city centres is one of the environmental problems. Defining the noise level is possible in two ways - via in situ measurement or via calculation (prediction). For the comparison of objectively measured values of sound pressure levels from railroads two methods used in the Slovak Republic were chosen - Schall 03 and the Czech prediction method. Track number 170: Zvolen-Vrútky in the town Zvolen was selected as the measurement location of noise exposure. Method Schall 03 overestimates the measurement values by approximately $1 \mathrm{~dB}$ and the Czech method by $4 \mathrm{~dB}$. Both prediction methods, in spite of the systematic overestimating, describe the real noise situation very well; the calculated Pearson coefficient of correlation with Schall 03 method was 0.94 and with the Czech method 0.90 .
\end{abstract}

DOI: $10.12693 /$ APhysPolA.127.125

PACS: 43.50.Lj, 43.50.+y

\section{Introduction}

The railway noise is an ongoing environmental issue. The purpose of legislation is the protection of health, quality of life and well-being of the population. While exploiting the environment by emissions of significant quantities of acoustics energy, management of a road, a railway, an airport is required to continuously monitor such emission $[1,2]$. The noise level can be evaluated in two ways - in situ measurement and calculation (prediction).

The comparison of these two methods - in situ measurement and prediction models - was the research objective of several authors [3]. Van Leeuwen [4] identified the inherent differences in various models. These differences include the assumption of source positions, the levels of noise emitted by trains passing by, the characteristics of sound radiation and the correction factors adopted to account for the effect of reflection. In light of this, the predicted noise levels are invariably different for different prediction models [3].

The basis is always represented by the data measured from the noise exposure compared to specific prediction methods. Traffic noise prediction models are required as aids in the design of highways and other roads and sometimes in the assessment of existing or envisaged changes in traffic noise conditions [5]. This effect is usually measured by the time-average sound level, $L_{\mathrm{AeqT}}$, or the sound exposure level pressure, $L_{\mathrm{AEX}}[6]$.

\footnotetext{
* corresponding author; e-mail: nemec@tuzvo.sk
}

The aim of our study is to compare selected prediction models used in rail transport with objectively measured values of sound pressure $L_{\mathrm{Aeq}}$. Two most frequently used models in the Slovak Republic were chosen to be compared: German prediction method - Schall 03 [7]; Czech prediction method - methodical instructions for the calculation of noise level from transport (MPVHD) [8].

\section{Overview of models for predicting train noise}

Method Schall 03 [7] was developed by Deutsche Budesbahn - German Railways. The basic emission noise level is calculated from the data obtained at the distance of $25 \mathrm{~m}$. Spreading of noise to the recipient depends on the position and reference noise level. Reference noise level was determined as an average noise level in one hour in the position of $25 \mathrm{~m}$ far from a moving train with a length of $100 \mathrm{~m}$, with speed of $100 \mathrm{~km} / \mathrm{h}$ with $100 \%$ share of disc brakes, in the height of $3.5 \mathrm{~m}$ over the terrain. The train was driving on a standard railroad track.

Emission level $L_{\mathrm{m}, \mathrm{E}}$ is calculated from Eq. (1):

$$
\begin{aligned}
& L_{\mathrm{m}, \mathrm{E}}=10 \log \left[\sum 10^{0.1\left(51+D_{\mathrm{Fz}}+D_{\mathrm{D}}+D_{\mathrm{L}}+D_{\mathrm{V}}\right)}\right] \\
& \quad+D_{\mathrm{Tt}}+D_{\mathrm{Br}}+D_{\mathrm{Lc}}+D_{\mathrm{Ra}}[\mathrm{dB}],
\end{aligned}
$$

where $D_{\mathrm{Fz}}, D_{\mathrm{D}}, D_{\mathrm{L}}, D_{\mathrm{s}}$ - corrections used for the specific train, $D_{\mathrm{Tt}}, D_{\mathrm{Br}}, D_{\mathrm{Lc}}, D_{\mathrm{Ra}}$ - corrections depending on the railroad track. $D_{\mathrm{Fz}}$ is used as a complement to fundamental noise level $51 \mathrm{~dB}$ and is given by the German Railways for all types of means of transport.

Prediction method MPVHD [8] has been used since 1977 and amended 1996. The newest legislative version of the valid predictive procedures for the calculation of noise on roads is "Methodical instructions for the calculation 
of noise level from transport", whose author is RNDr. Miloš Liberko. They include the calculation of noise from roads, rail roads; noise caused by trams and trolley buses, moreover the calculation of noise on parking places and from planes. The fundamental equivalent level of sound pressure $Y$ is calculated from Eq. (2) and for the distance $7.5 \mathrm{~m}$ from the railroad track axis or axes in the case of multiple-track roads following equation is valid:

$$
Y=10 \log X+40 \text {. }
$$

Value $X$ is calculated from equation

$$
X=140 F_{4} F_{5} F_{6} m,
$$

where $m$ is the number of trains per hour, $F_{4}$ express the influence of the traction divided into motor and electrical traction, $F_{5}$ is the factor of instantaneous speed in the given track part and $F_{6}$ is factor expressing the number of wagons in a train.

\section{Measurements of train noise}

Track number 170: Zvolen-Vrútky in the town Zvolen was selected as the measurement location of noise exposure. This track connects towns Zvolen, Banská Bystrica, Martin and Vrútky. Its overall length is $96 \mathrm{~km}$. The measurement location was selected due to a high frequency of rail transport leading through a densely inhabited part of the town Zvolen. In this part, besides a hospital, also houses and public buildings are located. The measurement was carried out along this track in the town Zvolen, specifically in front of the hospital near the railroad station "Zvolen mesto".

Selected measurement location is advantageous due to the fact that there are very few cars passing by. Before the train passes by the railroad crossing closes and stops the car transport - this decreases the residual noise level from the road transport. When measuring noise exposure in the outside environment the methodology presented in the standard STN ISO 1996-2 Acoustics Description, measurement and evaluation of noise in the outside environment Part 2: Setting of noise levels in accordance to requests [9] was followed.

Measurement was carried out on 3rd October 2011 on one measurement location within $12 \mathrm{~h}$ beginning at $6 \mathrm{am}$ and ending at $6 \mathrm{pm}$ (time interval - a day). Weather conditions were suitable to carry out the measurement (temperature was from $5{ }^{\circ} \mathrm{C}$ to $25^{\circ} \mathrm{C}$, wind speed was to $2 \mathrm{~m} / \mathrm{s}$ and the atmospheric humidity was within the range $75-90 \%)$.

Selected track is used by the inhabitants for the transport to work and schools to Zvolen and Banská Bystrica. During the measurement 41 trains passed along the track, of this 26 slow trains, 3 special trains, 7 express trains, 2 freight trains and 3 maintenance trains. Measurement analysis found out that the highest noise exposure was between 8 am and 9 am due to the high intensity of railroad transport and one freight train passing by. The lowest exposure was recorded between 10 and 11 am due to the lowest frequency of trains passing by at that time (one train in an hour).

\section{Comparison with the prediction models}

As we mentioned, two prediction methods were selected for the comparison with measured equivalent sound pressure levels. Figure 1 illustrates the evaluation of comparison of these prediction methods with the measurement in individual time intervals. Connection between individual sound pressure levels in individual intervals serves for a better orientation and interpretation of the differences between individual methods.

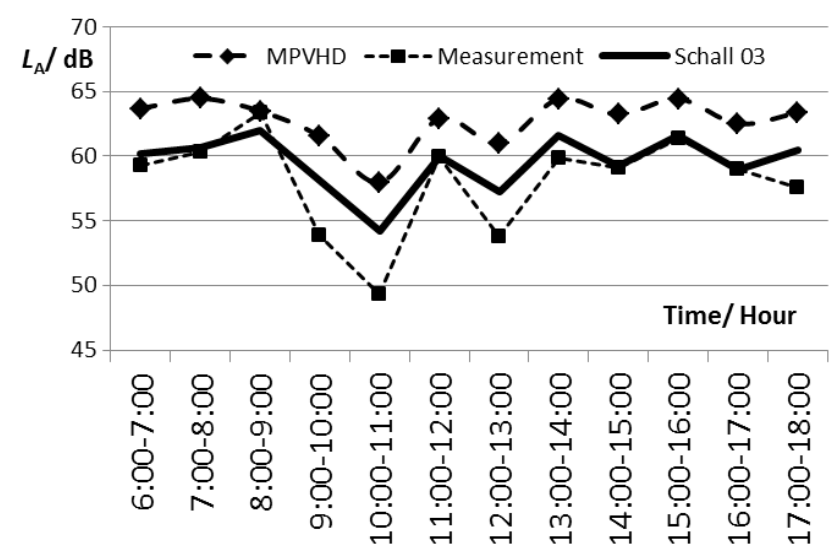

Fig. 1. Comparison of prediction models with the measurement.

Figure 1 shows that both prediction methods overestimate systematically the sound pressure levels determined by the measurement. Figure 1 shows that prediction method Schall 03 overestimates systematically the sound pressure levels determined by the measurement less. With extremely low values this difference is more significant in case of both prediction methods.

Due to the fact that both prediction methods are statistically dependent on the measured values, the paired $t$-test was selected for the statistical testing. The results are illustrated in Table. In both prediction methods statistically significant dependence on measurement was calculated (Pearson coefficient of correlation). It implies that both prediction methods describe, despite the systematic overestimating, the real noise situation very well.

Results of statistical testing via the paired $t$-test.

TABLE

\begin{tabular}{l|c|c|c}
\hline \hline & Schall 03 & MPVHD & Measurement \\
\hline average & 59.51 & 62.75 & 58.06 \\
STDEV & 2.21 & 1.85 & 3.88 \\
variance & 4.89 & 3.44 & 15.13 \\
sample size & 12 & 12 & 12 \\
Pearson corr. & 0.94 & 0.90 & \\
difference & 0 & 0 & \\
degree of freedom & 11 & 11 & \\
$t$ stat & -2.57 & 6.90 & \\
$P(T \leq t)(1)$ & $1.29 \times 10^{-2}$ & $1.28 \times 10^{-5}$ & \\
$t$ crit $(1)$ & 1.80 & 1.80 & \\
$P(T \leq t)(2)$ & $2.58 \times 10^{-2}$ & $2.57 \times 10^{-5}$ &
\end{tabular}


Illustration via the Bland-Altman graph (Fig. 2) was chosen to demonstrate the difference between prediction method Schall 03 and MPVHD graphically [10]. These are simple graphs where the horizontal axis (thin line) contains measured data of equivalent sound pressure level and vertical axis contains the differences between measured and predicted values. Graphs are supplemented with a horizontal line illustrating the average difference between measured and predicted values. Few facts are obvious from the Bland-Altman graph at first sight: the average difference between the measured and predicted values using Schall 03 method is smaller than in the case of MPVHD method; the use of Schall 03 method provided more values which vary less from the measured values; when using the MPVHD method all measured sound pressure levels were overestimated, while during the use of Schall 03 method only some measured values of sound pressure were underestimated which, in the end, has a positive influence on the objectivity of the value of sound pressure equivalent level in the reference time. This value is a result of noise exposure evaluation in the given location using prediction models. Following these facts it is possible to decide which prediction method describes the real noise exposure better.

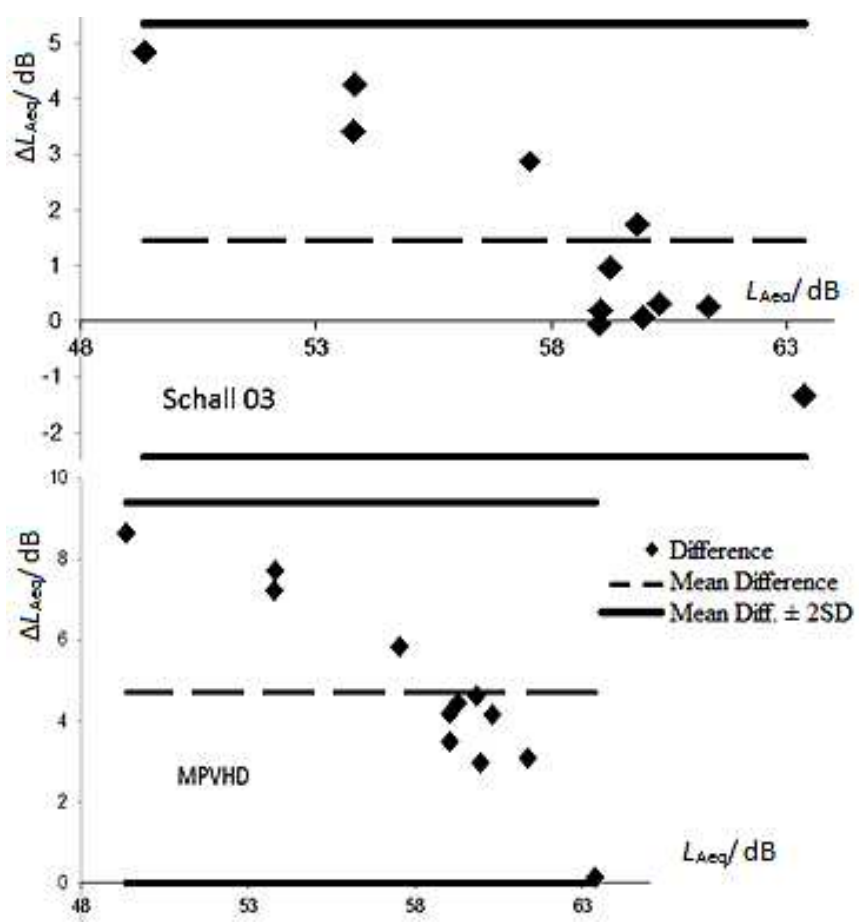

Fig. 2. Comparison of prediction methods via the Bland-Altman graphs.

\section{Conclusions}

Measured values of sound pressure levels from the railroad transport were compared to two prediction models used in the Slovak Republic. The measured value of sound pressure for the reference time (6 am-6 pm) $L_{\text {Aeq,12h }}$ was $59.3 \mathrm{~dB}$. The results have shown that both prediction models overestimate the measured values systematically. Method Schall 03 overestimates by approximately $1 \mathrm{~dB}\left(L_{\mathrm{Aeq}, 12 \mathrm{~h}}=59.9 \mathrm{~dB}\right)$ and the MPVHD method by $4 \mathrm{~dB}\left(L_{\mathrm{Aeq}, 12 \mathrm{~h}}=63.0 \mathrm{~dB}\right)$. Both prediction methods, in spite of a systematic overestimating, describe the real noise situation very well because the calculated Pearson coefficient of correlation with Schall 03 method was 0.94 and with the MPVHD method 0.90. Based on the found results it can be stated that the prediction model Schall 03 is more suitable for the conditions in the Slovak Republic. The use of this model is also embodied in the legislative of the Slovakia.

\section{Acknowledgments}

The research described in this paper was financed jointly by the KEGA (Project No. 016TUZ-4/2012), VEGA (1/0538/14) and OP RAD EU (ITMS 26220220169).

\section{References}

[1] M. Kłaczyński, T. Wszołek, Acta Phys. Pol. A 121, A-179 (2012).

[2] P. Leśna, E. Skrodzka, Acta Phys. Pol. A 118, 115 (2010).

[3] W.K. Lui, K.M. Li, P.L. Ng, G.H. Frommer, Appl. Acoust. 67, 432 (2006).

[4] H.J.A. van Leeuwen, J. Sound Vibrat. 231, 975 (2000).

[5] C. Steele, Appl. Acoust. 62, 271 (2001).

[6] R. Makarewicz, M. Yoshida, Appl. Acoust. 49, 291 (1996).

[7] German Railways. Guideline on the calculation of railway noise, Schall 03/Akustik 03, Munich 1990 (in German).

[8] M. Liberko, Traffic noise. Guidelines for calculating levels of traffic noise, VÚVA, Brno 1991, novel from 1996, Vol. XII, No. 2/2005 (in Czech).

[9] STN ISO 1996-2, A2 Acoustics. Description, measurement and assessment of environmental noise. Part 2: Determination of environmental noise levels, 2008 (in Slovak).

[10] M. Dado, M. Schwarz, M. Frič, Akustika 17, 2 (2012). 